\title{
The Samurai physician. Negotiation styles for informed consent and conflict mediation
}

\author{
Virginia Recchia $^{1}$ and Antonio Dodaro ${ }^{2}$ \\ ${ }^{1}$ CNR-IFC National Research Council-Institute of Clinical Physiology \\ ${ }^{2}$ Affiliation not available
}

February 1, 2022

\begin{abstract}
Nowadays, patient-centred practice represents the key for quality and successful outcomes in healthcare. At the same time, shared decision-making is acknowledged as the highlight of patient-centred care. Informed consent, whenever derives appropriately from a two-way communication between doctor and patient, follows a negotiation process that leads to appropriate and shared decisions. This article aims to show how the typical negotiating styles can lead or not to effective informed consent and conflict mediation processes. To this end, the three negotiating styles currently theorized (sharks, saints, and samurai) are integrated into the three clinical models of doctor-patient interaction (paternalistic, interpretative and autonomist). Currently, being any paternalistic attitude disapproved both ethically and legally, the model of autonomy is the only suitable one to communicate effectively. A concrete case from cardiology is reported to show the different negotiation styles within a doctor-patient conversation. Upstream, drawing inspiration from the samurai negotiating style, the doctor could find a new approach to effective informed consent. Downstream, during mediation, he/she could recompose all those conflicts that stem from an unsatisfying relationship with the patient. These results suggest, finally, that the physicians should be aware of their own prevalent negotiating style and of how to improve it if necessary.
\end{abstract}

TITLE: The Samurai physician. Negotiation styles for informed consent and conflict mediation in healthcare

SHORT TITLE: Negotiation, informed consent and health mediation

Abstract: Nowadays, patient-centred practice represents the key for quality and successful outcomes in healthcare. At the same time, shared decision-making is acknowledged as the highlight of patient-centred care. Informed consent, whenever derives appropriately from a two-way communication between doctor and patient, follows a negotiation process that leads to appropriate and shared decisions. This article aims to show how the typical negotiating styles can lead or not to effective informed consent and conflict mediation processes. To this end, the three negotiating styles currently theorized (sharks, saints, and samurai) are integrated into the three clinical models of doctor-patient interaction (paternalistic, interpretative and autonomist). Currently, being any paternalistic attitude disapproved both ethically and legally, the model of autonomy is the only suitable one to communicate effectively. A concrete case from cardiology is reported to show the different negotiation styles within a doctor-patient conversation. Upstream, drawing inspiration from the samurai negotiating style, the doctor could find a new approach to effective informed consent. Downstream, during mediation, he/she could recompose all those conflicts that stem from an unsatisfying relationship with the patient. These results suggest, finally, that the physicians should be aware of their own prevalent negotiating style and of how to improve it if necessary.

Keywords: patient-centred care, medical ethics, humanity, health services research, clinical guidelines, negotiation 


\section{Virginia Recchia}

Research Scientist

Health Risk Communication and Patient Engagement

CNR-IFC Italian National Research Council - Institute of Clinical Physiology

C/O Ecotekne University Campus

Strada Prov.le Lecce-Monteroni

73100 Lecce - Italy

Phone: +39-0832-422314

Mobile: +39-320-1421681

Fax: $+39-0832-422340$

Email: recchia@ifc.cnr.it

\section{Antonio Dodaro}

Legal Expert and Independent Researcher

Bioethics, Health Mediation and Informed Consent

73100 Lecce, Italy

Email:antonio.dodaro@hotmail.it

\section{Introduction}

At international level, different schools of negotiation suggest theoretical frameworks for an improvement of interpersonal relationships. Among the many relevant interactions in social life, the one between the doctor and patient is known for its crucial importance for the clinical outcomes. ${ }^{1}$ In the context of this relationship, some authors propose that the concept of negotiation is an integral part of the physician's activity. ${ }^{2-5}$ Negotiation, in fact, means a two-way communication aimed at reaching an agreement, when two or more counterparts have some interests in common and others in contrast. ${ }^{6}$ Without carrying out this process, which requires the active participation of both parties, the physician can encounter serious difficulties in motivating the patient. Excluding all acute conditions, where scientific guidelines suggest a treatment almost certainly, about $50 \%$ of the treatments do not have a reasonable evidence to suggest a decision on one side or on the other. ${ }^{7,8}$ In all these cases, the doctor must share the clinical decision with the patient. This is one main reason why recent literature recommends shared decision-making, which is the participation of patients and their engagement in the choices, as the ideal solution for the effectiveness of health treatments. ${ }^{9-12}$

Nevertheless, in the ambitious goal of achieving personalized medicine, thanks above all to diagnostic and therapeutic technology-based approaches, there is the danger of losing what is really personal in medicine, that is the interaction between a doctor and his/her patient. ${ }^{13}$ Some studies, moreover, show that the effectiveness of this interaction is one of the most relevant solutions to medical errors, which, for instance, in the US now represent the third cause of death, after cardiovascular diseases and cancer. ${ }^{14}$

Negotiation often takes place in clinical settings, whenever communication aims at interpersonal exchange for achieving a specific aim, which may be treating the patient or - in the case of chronic or incurable disease maintaining his/her state of suffering within the limits defined by his/her own will. This negotiation process can continue even after patient care, in particular when a conflict occurs, that is, when the agreement between the patient and the doctor - implicit or explicit - is not successful and could be recomposed through mediation. ${ }^{15,16}$ Informed consent is one of the main tools to guarantee a shared choice, namely that the 
patient has effectively understood and balanced risks, benefits and alternatives to arrive at a solution that is correct for his/her state, having also contemplated his/her own values and interests.

The literature, indeed, increasingly documents that involving patients in decision-making through effective communication reduces the risk of litigation. ${ }^{17-21}$ Including patients in decisions, by using tools that help them balance risks and benefits, standardising clinical communication, and reducing their awe towards doctors may also contribute to reduce the amount of clinical procedures, increasing their appropriateness and eliminating the undesirable effects on outcomes and satisfaction. ${ }^{22}$

This article aims to analise how the typical negotiating styles might lead or not to a real informed consent and shared decision-making. To this end, the three negotiating styles currently theorized (sharks, saints, and samurai) are integrated into the three clinical models of doctor-patient interaction (paternalistic, interpretative and autonomist). The results show how each of these styles can lead to different outcomes in case of conflict and consequent mediation.

\section{The different styles and negotiating powers applicable to informed consent}

The concept of negotiation emphasizes the essential and personal equality between doctor and patient, as well as the need for an agreement between the two parties about the problem and its management, so that the clinical consultation can be successful. ${ }^{2,23}$

The main schools of contemporary negotiation belong to two research mainstreams. ${ }^{24}$ The first school is that of the so-called "sharks", inspired by Herb Cohen in the book "You can negotiate anything" ${ }^{25}$, while the second school is that of the so-called "saints", under the directives by Roger Fisher and William Ury in the book "Getting to yes" ${ }^{26}$. The school of the sharks places its emphasis on negotiating power and on a set of techniques through which to gain an advantage over the interlocutors, according to a view named "win-lose" (in which there are a winner and a loser). The school of the saints, instead, focuses on the constructive integration of interests, while at the same time laying the foundations for a relationship that goes beyond the single negotiation, according to an enlightened vision named "win-win" (in which there are two winners). Both the theoretical frameworks agree that ethics is in principle a weakness, which we should accept at the service of a larger aim and often at the cost of giving up some real power or potential negotiation, with the result of a lower profit.

Ethics are defined as a set of values, principles, and rules commonly accepted by society, which guide human behavior and relay how human behaviors can touch not only their own lives but also the others' lives. ${ }^{27}$

Shell ${ }^{28}$ argues that a smart shark negotiator uses ethical tactics to gain an advantage. Like any good seller, he/she exercises - at least verbally - the softer aspects of the interaction, showing human interest to the interlocutor, and chatting to encourage co-participation. He/she can resort to rules of fairness, especially when there is at stake an unattractive and unexpectedly hard proposal for the other party. However, this negotiator does everything to gain the trust of his/her interlocutor, knowing in practice that without this trust he/she cannot reach a sustainable agreement, no matter how weak his/her interlocutor is. ${ }^{29}$

According to the thought of the saints, while in the short term the exercise of power can work in the pursuit of immediate interests at the expense of the other party, in the long term it does not work and you are destined to pay a high price. Therefore, an intelligent negotiator does much more than showing ethical behavior in words. $\mathrm{He} / \mathrm{she}$ really wants to honor his/her precepts and thereby makes sure that his/her offerings are sustainable and protect his/her general reputation. Following the rules of an enlightened egoism, he/she is ethical and is interested in the interlocutor as an individual, taking care of the relationship as well as the content of the discussion. He/she sincerely seeks ethical standards or joint criteria by which to measure the results of the negotiations and ensures that they are fair for both the parties. Even at the cost of giving up the gains of an aggressive negotiation, he/she will never betray trust or engage in cheap and shoddy tricks. $\mathrm{He} / \mathrm{she}$ is too far-sighted for this; too aware that in the end these tactics can never really pay. ${ }^{26,29}$

More recently, Mark Young ${ }^{29}$ has identified a third approach to the use of ethics in negotiation, inspired by the behavior and negotiating power of the ancient "samurai". In this strand of negotiation, the author has 
identified a behavior inspired by ethics per se, which is then pursued according to a view of principle and without worrying about the consequences, advantageous or disadvantageous. Far from making the classic game of negotiation shrewd or more enlightened, the samurai negotiators choose to completely change the rules of the game, valuing ethics per se, not worrying about the balance between ethics and power, and enjoying the power that they generate as an associated effect.

The samurai were erudite and educated warriors, bound by a code of ethics - the Bushido ${ }^{30}$ - that was much more demanding than that of the western cavalry, and therefore highly respected by all, friends and enemies. The Bushido code bound its members to a strict adherence to the values of sacrifice, loyalty, piety, respect, honesty, compassion for the weak person, calm, equity, and justice, to name a few. ${ }^{30}$ The samurai practiced all of this solely because he understood the value of the other and knew that these rules were essential to society. Likewise, the negotiator who uses a samurai style feels constrained by the rules and does not dwell on measuring the effects of this behavior on his profits and results.

Table 1 summarizes and compares the negotiating styles related to the three scientific schools and their approaches to ethics, highlighting their tools, solutions and justifications.

The same negotiation techniques above described can be adopted in the context of the medical relationship. Therefore, this article assumes that there are three fundamental approaches to physician-patient relationship, which can be linked to three profiles of doctors-negotiators and related hypotheses of negotiating power and ethical approaches in medicine.

Medical ethics consists of a set of values which medical personnel may refer to and which are incorporated into their professionalism. A scarce observance of medical ethics not only threat to damage physician-patient relationship, but may also boost inadequate health services. ${ }^{31}$ Four basic principles (autonomy, justice, beneficence and non-maleficence) are the basis of medical ethics. ${ }^{32,33}$ These ethical principles are grounded on the foremost historical references in this field, which are Hippocratic Oath, Nuremberg code and Helsinki declaration.

The principle of respect of autonomy underlines that the patient has the right to refuse or accept the treatment suggested by the medical personnel. Beneficence points out that every doctor should act in the patient's best interest. Non-maleficence requires the doctor not to be the cause of damage. Justice concerns the equity in allocating scarce health resources, and the choice regarding which patient should receive what treatment. ${ }^{32,33}$

In the following paragraph, it is described how each negotiating style corresponds to a different approach to medical ethics.

\subsection{The style of the shark doctor}

The first approach regards the doctor who uses a "shark" style of negotiation, which is devoid of any ethical scruple, and - if anything - uses ethics solely for its own purposes. This type of doctor orients his/her action exclusively towards the successful result at all costs. This successful result consists in making one's own will prevail over that of the patient, basing one's power on one or more ideal reputed technique. From the viewpoint of a shark doctor-negotiator, in fact, the patient degrades to a person who is not considered, and who - even in his/her abstract interest in health - can only suffer. This perspective leads the physician to threaten the interests as well as the profound and inviolable values for the sick person.

A shark doctor is a person who is also animated by good intentions about the healing of his/her patient, but who does not know empathy and relational sharing with the patient. This is typically the paternalistic doctor who does not involve the patient in the decisions, informs roughly or avoids information, prescribes diagnostic and/or therapeutic procedures, even inappropriate, in order to get the immediate advantage of seeming professionally effective for having solved the clinical problem.${ }^{34}$ Often it is the same professional who performs a "defensive medicine", that is a medicine conducted not so much to ensure the health of the patient, but as a guarantee on the medical-legal responsibilities resulting from the diagnosis and care provided. This doctor, on the basis of his/her greater basic negotiating power, due to the informative and 
cognitive asymmetry with respect to his/her patient, obtains its own advantage in the short-term, neglecting the fact that in the long-term this advantage may sometimes damage the health of its unaware counterpart. This behavior is widespread and often coincides with the "commission bias", i.e. the wrong tendency to do something anyway, overestimating the benefits and minimizing the risks of the diagnostic or therapeutic procedure. ${ }^{35}$

\subsection{The style of the holy doctor}

The doctor who uses a "holy" style of negotiation assumes an attitude aimed at the win-win result, that is, he/she engages in trying to integrate its own interests and values with those of the patient. Integration is always ethically and clinically desirable, and is embodied into the attitude of a doctor-negotiator well prepared for an open and yet cautious dialogue with the patient and his/her family. The holy doctor is certainly an ethical negotiator, as he/she wants to build a long-lasting interpersonal relationship, based on trust and mutual influence, just as the same medical deontology requires starting from the Hippocratic oath. $^{36}$

In other words, the holy doctor focuses on creating a human relationship strictly required by the professionalism connected to its role, both from the clinical and from the ethico-legal viewpoint. This doctor who uses a holy negotiator style - informs the patient, in order that he/she will trust him/her and will be more compliant in following his/her directions. ${ }^{17,19} \mathrm{He} /$ she uses an ethical approach, since he/she believes that some integration of interests with the patient can bring benefits to both, and this attitude ultimately increases his/her power and influence. At the same time, he/she invests in some form of relationship with the patient that can go beyond the momentary performance. Nevertheless, he/she does so from an instrumentalist viewpoint, and not because he/she aims to adopt behaviors that are right in themselves and in principle.

\subsection{The style of the samurai doctor}

The doctor who uses a "samurai" style of negotiation is the one who communicates with the patient because this responds to universally shared values, first and foremost the patient's autonomy. ${ }^{36} \mathrm{He} /$ she does not care about the consequences, including the fact that as a result of the established communication process the patient could decide not to adhere to a suggested therapy or not to undergo a prescribed diagnostic procedure. ${ }^{37}$

The samurai doctor acts in the name of the ethical and deontological values of reference, in which he/she firmly believes, and works in the name of achieving the highest health good. His/her professional behavior consists in an indistinct continuum between power and ethics. From this perspective, ethics is always the right pathway to pursue, even when it is the most difficult. The attitude to do the right thing translates into being a credible and admired doctor, which generates a sense of respect on the part of the patient, based on real trust.

Being a samurai physician means to assume ethically, even before than clinically and legally, a responsibility connected to a clinical decision, without any hesitation in terms of communication with the patient and his/her loved ones, and in the context of a truly informed consent and shared decisions. What most of the doctors miss in implementing defensive medicine as the only possible practice, is in that this alternative ethical action in many cases does not diminish the negotiating power, but rather increase it.

\section{The integration between clinical and negotiation models of doctor-patient interaction}

This article argues that each model of physician-patient interaction representative of the different epochs in the history of medicine ${ }^{38}$ naturally lends itself to embodying a corresponding negotiating model (Table 2). The paternalistic model has stood for thousands of years because it founded in the past on a high evaluation of ethics. The doctor felt and was actually entitled to decide in the interest of the patient without the latter participating in those choices. Therefore, according to this model - founded on a fiduciary pact - the doctor assumed a status of superiority and centrality, while the patient assumed a position of cognitive inferiority, by virtue of which he/she limited himself/herself to follow the prescriptions carefully. Within the paternalistic 
model, in fact, it was usual assuming that the interaction between physician and patient is asymmetric (or unequal) due to the physician's authority, grounded on its expert status and superior knowledge. ${ }^{39,40}$

More recently, since cognitive and informative asymmetry has diminished, the paternalistic physician makes a purely instrumental use of ethics in the decision-making process. This type of doctor aims to prevail (sometimes even with noble purposes) on his/her interlocutor, in a win-lose perspective. He/she often imposes certain hurry to the patient to decide, showing not empathy but rather detachment. Most often, he/she does not want to conduct a consultation on a level playing field. He/she does not offer many explanations on diagnostic-therapeutic choices or - if he/she does - uses a technical language, without worrying that the patient has fully understood the message.

The doctor who refers to an interpretative model, while providing a form of interaction and integration of interests between himself/herself and the patient, does so because he/she considers it necessary to meet the goals of both. In this model, therefore, the use of ethics is instrumental in getting both to benefit of the established relationship, in a win-win perspective.

The informative or autonomist model is the one most suited to the use of a samurai medical negotiation style. This model facilitates communication as the most correct means of achieving the patient health, beyond what the doctor himself/herself can benefit from. Without giving any pressure, the clinician not only explains the available options and the relative risks in a simple way, but also worries to verify if the patient has fully understood everything. ${ }^{5,41}$ The patient is truly engaged, being him/her at the center of the interaction and negotiation processes that are necessary to put in place the most opportune decisions. At the state of the art, there is no broadly acknowledged definition of patient engagement, although this notion implies that patients should be actively involved in their healthcare. This means gathering and reworking information, deciding how diagnostic and therapeutic procedures are suitable for their lives, and consequently moving towards fulfilling those decisions. ${ }^{42}$

Concrete examples of conversations belonging to the three models of doctor-patient interaction and negotiation styles are provided in Table 3, in order to raise some further insights connected to the actual clinical practice.

\section{The value of the samurai negotiation style in informed consent}

Doing the right thing, and then adopting an ethical behaviour - essentially based on universal values - means temporarily setting aside one's own interest and connecting to the other party in a trust agreement that integrates interests and values belonging to both parties. Within informed consent, doing the right thing and behaving in an ethical way means arriving at the sharing of interests and values through communication on a whole series of relevant knowledge and negotiation of related decisions. This knowledge, only if analyzed and shared by the parties, forms the legitimacy of pursuing an overall diagnostic or therapeutic goal within a real therapeutic alliance. The therapeutic alliance, in fact, is a broad construct that commonly embraces the collaborative spirit, the emotional connection, and the goal and task agreement between patients and clinicians. ${ }^{43}$

Knowledge sharing must necessarily focus on the analysis of the risks and benefits of a certain medical act as well as on the analysis of the risks and benefits of the alternatives, i.e. the possible options available and feasible for that patient and in that given setting. All this in the context of an open and frank dialogue, where the human and clinical doubts by the doctor are integrated with the human, clinical and emotional doubts by the patient necessitating answers and empathy.

As a virtuous effect, the attitude and behavior of a samurai turn into negotiating power by the doctor, since the patient really trusts him/her, deeming him/her worthy. ${ }^{17,19}$ Actually, esteem and trust are not and cannot be a tribute to the mere technical competence of a physician. They are always the result of a deep ethical respect for the personal interests and values by the doctor towards the patient, and are generally made explicit through attentive listening to his/her needs. Finally, respect and listening must merge in the same completeness of communication and sharing of choices, in the right way and at the right time before 
executing the medical act of diagnosis or treatment.

A physician who negotiates in an ethical way creates an interpersonal relationship in which the communicative and relational process generates an effective informed consent. The latter is in itself also a negotiation process that, if really applied, can drastically reduce the clinical and organizational inadequacy, as well as the insurance, judicial and deontological litigations linked to unfortunate events. ${ }^{17}$ Sharing salient information about a risky and/or invasive medical act is, in fact, the only real way to give substance to the abstract concept of clinical and organizational appropriateness, while preventing many acts of malpractice.

The fact that the physician is in contact with the patient in need of help respecting his/her feelings before executing the potentially dangerous and/or invasive clinical act certainly translates into an ethical professional behavior. ${ }^{44}$ This behavior can be traced back to a samurai behavior, with its code of life and honor. ${ }^{36}$

The ethical attitude of a doctor who performs a properly informed consent process makes him/her free to express all the eventual technical doubts about a specific pathological condition. The technical doubts may contrast with those of the patient, but all these doubts together should result from a complete analysis of the available options (See Table 3). Such options should balance the patient's values and interests, with different degrees of risk-benefit that the doctor must easily illustrate, under penalty of conduct that can be pursued from a legal point of view. ${ }^{45}$

The doctor who respects the patient's autonomy adopts a behavioral style and an attitude that is not only collaborative, but also aware of his/her empathetic competence with regard to the patient's doubts, emotions and information needs. This professional stands as a subject and actor who is responsible for good health per se, like the samurai who uses his/her physical strength by channeling it into a fine fighting technique, according to a lifestyle respectful and sensitive especially of the neediest and defenseless. In this sense, the samurai doctor considers all indications of clinical relevance, including the fears and emotional repercussions experienced by those who suffer. Listening to the symptoms and emotions of the patient does not distract the samurai doctor from his/her role as interpreter of health problems. The samurai doctor negotiates his/her own emotional and professional orientation with the emotional and value orientation of his/her patient. $\mathrm{He} / \mathrm{she}$ takes a responsible position on the choice of a diagnostic and/or therapeutic technique, but he/she does so respecting the patient's perspective and feelings.

This style and negotiating power vanish in every doctor who believes that the mere signature of a patient on the informed consent form represents the ethical and legal solution to avoid various consequences related to the function performed in exercise of the same profession. In informed consent achieved as the signature of a form there is nothing related to a fiduciary relationship, which can only be built between doctor and patient through active listening and feedback. This communication generates a true relationship between doctor and patient when the former is able to negotiate with the latter on a treatment to be proposed and chosen. $^{46}$

On the contrary, the attitude of the shark physician occurs when he/she manages informed consent as a bureaucratic event of mere signature of the form. This behavior is, inter alia, legally ineffective. When the doctor does not negotiate anything and asks the patient to sign a standard consent form for purely legalistic purposes, if the clinical act generates an unfortunate event, that consent does not relieve the same doctor from any responsibility, not morally nor legally. This deterioration of the professional attitude in the health sector is certainly a source of legal responsibility that can be attempted to repair through health mediation. This procedure typically precedes the initiation of a judicial procedure for medical fault, with the scope to avoid it. In the healthcare context - as described in the following paragraph - with the help of a third party (namely the facilitator) it is possible to try to act on the relational and communicative damage that an inappropriate informed consent may have determined in the concrete clinical situation.

\section{Conflict and health mediation in the samurai style}

Being that between doctor and patient a particular contractual relationship, it can - like any contractual relationship in which the agreements are not respected - generate conflicts that need mediation. Based on a 
common practice, people carry on contractual relations in a correct and fair way. In this context, a correct behavior can be defined as a behaviour that is acceptable to the society and conforming to common social values and principles. In this sense, the correctness is "determined by social agreement" ${ }^{47}$ In parallel, a fair behaviour is defined as "acceptable and appropriate in a particular situation", ${ }^{48}$ and "conforming to an established commonly accepted code of rules of a game or competitive activity". ${ }^{49}$ Consequently, fairness determines "the absence of discrimination in a decision making process" ${ }^{50}$ Often, the sanction reserved for the uncorrect and unfair person invests the reputation, and this is more incisive than any other sanction foreseen by law. ${ }^{51}$

A typical case of breaking the agreement - often with legal consequences - is that in which the patient overestimated the benefits and underestimated the risks of a treatment. ${ }^{7}$ However, the doctor himself/herself can induce this situation, ${ }^{52}$ through the more or less conscious use of strategies that can prevent the patient understanding and participating in the decision.

When a conflict occurs between the doctor and the patient, the mediator takes a facilitating function between the parties, behaves like the witness of any unethical behavior and may act promptly to remedy them. This is possible by adopting various measures on relational correctness: (a) maintaining the mediation procedure on socially acceptable tracks; (b) threatening to stop it whenever it is impossible to continue, (c) ceasing the procedure if a correct level of interpersonal relationship is not restored. ${ }^{53}$ It is therefore essential to illustrate how to behave ethically within the relationship between the parties. We have seen the use of ethics by the samurai, but this is only one example among the many existing in the social universe. Certainly one party cannot deceive or omit - to reach a more favorable agreement - some important elements or some information that, if known on the other side, would induce it to a different choice. ${ }^{54}$ If somebody does not take part in person, but as a representative of a party, he/she cannot exceed the limit agreed with the represented party, to not generate false expectations in the other party or to not obtain resources that cannot be counterbalanced. Parties cannot fail the word given or deny what said to cover some errors or indiscretions. Rather, it is preferable that they acknowledge they have made a mistake, also gaining credibility. ${ }^{53}$

The mediator acts as an ethics' supervisor in the procedure, since he/she knows that its conclusion depends on the correctness and on the concrete honesty demonstrated by both the parties. The same honesty must ideally be demonstrated already upstream, in an initial equitable agreement, or - in the absence thereof after the mediation, in the final contract. In fact, in this phase, the expectations of one part balance with those of the other, in terms of satisfaction of the interests, values and needs of both. This mechanism there exists also in the social contract between doctor and patient, which sees the obligation to implement a valid and effective informed consent process, to compensate the existing information and cognitive asymmetry between the two. ${ }^{15}$

To make a balanced contractual exchange, the best guarantee of execution of the agreement is given by the fact that no party feels disadvantaged in the solution reached, which will indeed be the best possible with respect to the specific dispute. ${ }^{55}$ In the same way, a correct informed consent process guarantees that not only the health professional - who possesses the information and knowledge inherent the contractual relationship - but also the patient is aware and satisfied with the diagnostic or therapeutic proposal. ${ }^{56,57}$

Being aware of his/her prevailing negotiating style - even in private life - is strategically important for anyone. This awareness allows, in fact, the understanding of one's potential negotiating power, that is, how much capacity one possesses in being able to interact with one's counterpart in the pursuit of a defined purpose. Focusing on one's own style and negotiating power is a good way for the doctor to understand what kind of prevalent approach he/she should adopt in the specific work context. Therefore, based on the study and daily application of the best negotiation techniques, the doctor could obtain the following advantages:

a) Setting up a valid communicative process of informed consent, with the aim of creating and maintaining a real therapeutic alliance and an effective professional relationship with the patient over time.

b) Attempting to reconstruct, through health mediation (also based on the use of negotiation techniques), a therapeutic alliance that was absent at the origin or unfortunately deteriorated in a conflict. This deteri- 
oration, as highlighted, is often due to a total lack or poor management of the communication process and informed consent.

\section{Conclusion}

The communicative and negotiating styles considered in the context of this article are nothing more than ideal types. As such, therefore, they function as simplifications useful for descriptive purposes. Indeed, the reality is much more multifaceted and it is up to the practitioner to decide whether a shark, a saint or a samurai behaviour should prevail in his/her work life.

As patient, everyone in the life can meet physicians who carry out their activities in full respect of the autonomy of the person and always share their decisions. These doctors are more successful and incur less than others in judicial litigation and in the spiral of defensive medicine. In fact, patient involvement and engagement is now part of an unavoidable need in the growing complexity of health management.

Moreover, for simplicity, the chosen unit of this analysis consists of the doctor-patient relationship. It is clear that this unit is reductive in reality, if we think of the hospital and territorial context, where the professional figures involved in the patient's communication and decision-making processes are much more. In this sense, the communication and negotiation styles described in this article can be applied to any professional involved in the clinical-care pathway, primarily when executing diagnostic-therapeutic procedures characterized by particular riskiness and/or invasiveness.

Finally, whenever the samurai negotiation model has not been pursued in the clinical-care pathway, it must be in any case adopted during the conflict among the parties. The health mediation, in fact, is the anteroom of a judicial procedure for medical fault, thus it is fundamental that the professional responsibly changes his/her attitude towards a full understanding of the interests and values of the patient. As if it was an oriental warrior who - even at the cost of losing personally - admits his/her mistake and recognizes in the "sick body" the person mistakenly not considered in the previous clinical phase. This attitude of loyalty and honesty, bringing back to the center the relational aspects - from which every conflict is often generated - allows an important reconciliation between the parties and is therefore an indispensable premise for a possible settlement of the disputy.

\section{References}

1. Levinson W. Patient-centred communication: a sophisticated procedure.BMJ Qual Saf. 2011;20(10):823-825. doi:10.1136/bmjqs-2011-000323

2. Lutz AG. Patients' autonomy as a negotiated order: an ethnographic perspective on the clinical management of childhood obesity. Sociol Health Illn. 2019;41(4):772-788. doi:10.1111/1467-9566.12863

3. Yelovich MC. The patient-physician interaction as a meeting of experts: one solution to the problem of patient non-adherence. J Eval Clin Pract. 2016;22(4):558-564. doi:10.1111/jep.12561

4. Mariscotti J. A delicate dance: negotiating the doctor-patient relationship during cancer treatment. Oncologist.2008;13(11):1205-1206. doi:10.1634/theoncologist.2008-0199

5. Krizova E, Simek J. Theory and practice of informed consent in the Czech Republic. J Med Ethics. 2007;33(5):273-277. doi:10.1136/jme.2005.015164

6. Fisher R, Ury W, Patton B. Getting to Yes: Negotiating Agreement Without Giving in. $2^{\text {nd }}$ ed. Houghton Mifflin; 1991.

7. Bobbio M. I pazienti di fronte alla decisione di sottoporsi ad angioplastica [Patients facing with the decision to undergo percutaneous coronary intervention]. Recenti Prog Med.2015;106(3):113-117. doi:10.1701/1806.19698

8. Godlee F, Smith R, Goldmann D. Clinical evidence. BMJ. 1999;318(7198):1570-1571. doi:10.1136/bmj.318.7198.1570

9. Ng CJ, Lee YK, Abdullah A, Abu Bakar AI, Tun Firzara AM, Tiew HW. Shared decision making: A dual-layer model to tackling multimorbidity in primary care. J Eval Clin Pract. 2019 Dec;25(6):10741079. doi: $10.1111 /$ jep.13163. 
10. Jenerette CM, Mayer DK. Patient-Provider Communication: the Rise of Patient Engagement. Semin Oncol Nurs. 2016;32(2):134-143. doi:10.1016/j.soncn.2016.02.007

11. Menichetti J, Libreri C, Lozza E, Graffigna G. Giving patients a starring role in their own care: a bibliometric analysis of the on-going literature debate. Health Expect. 2016;19(3):516-526. doi:10.1111/hex.12299

12. Graffigna G, Barello S, Riva G, Bosio AC. Patient Engagement: The Key to Redesign the Exchange Between the Demand and Supply for Healthcare in the Era of Active Ageing. Stud Health Technol Inform. 2014;203:85-95.

13. Fuster V. A second dilemma in cardiovascular medicine: personalized medicine versus personal interaction with the patient. J Am Coll Cardiol. 2014;64(12):1292-1293. doi:10.1016/j.jacc.2014.08.006

14. Makary MA, Daniel M. Medical error-the third leading cause of death in the US. BMJ. 2016;353:i2139. Published 2016 May 3. doi:10.1136/bmj.i2139

15. Dodaro A, Recchia V. (2014). The bi-directionality among informed consent process and mediation applied to healthcare conflicts.Prat Med \& Asp Leg. 2014;8(2):75-81. SEED Medical Publishers, Torino, Italy. doi: http://dx.doi.org/10.7175/pmeal.v8i2.920

16. Sandman L. The concept of negotiation in shared decision making. Health Care Anal. 2009;17(3):236243. doi:10.1007/s10728-008-0103-y

17. Hamasaki T, Hagihara A. Physicians' explanatory behaviours and legal liability in decided medical malpractice litigation cases in Japan.BMC Med Ethics. 2011;12:7. Published 2011 Apr 21. doi:10.1186/1472-6939-12-7

18. Levinson W, Lesser CS, Epstein RM. Developing physician communication skills for patient-centered care. Health Aff (Millwood).2010;29(7):1310-1318. doi:10.1377/hlthaff.2009.0450

19. Ha JF, Longnecker N. Doctor-patient communication: a review. Ochsner J. 2010;10(1):38-43.

20. Correia NG. Adverse events: reducing the risk of litigation. Cleve Clin J Med. 2002;69(1):15-24. doi:10.3949/ccjm.69.1.15

21. Moore PJ, Adler NE, Robertson PA. Medical malpractice: the effect of doctor-patient relations on medical patient perceptions and malpractice intentions. West J Med. 2000;173(4):244-250. doi:10.1136/ewjm.173.4.244

22. O'Connor AM, Bennett CL, Stacey D, et al. Decision aids for people facing health treatment or screening decisions. Cochrane Database Syst Rev. 2009;(3):CD001431. Published 2009 Jul 8. doi:10.1002/14651858.CD001431.pub2

23. Tseng PC. Subordinated agency: Negotiating the biomedicalisation of masculinity among gay men living with HIV. Sociol Health Illn.2021;43(6):1486-1500. doi:10.1111/1467-9566.13322

24. Wheeler M. Swimming with saints/praying with sharks. In: Menkel-Meadow C, Wheeler M, eds. What's fair: Ethics for negotiators. Jossey-Bass; 2004.

25. Cohen H. You can negotiate anything. Lyle Stuart; 1982.

26. Fisher R, Ury W. Getting to yes: Negotiating agreement without giving in. Penguin; 1981.

27. Bottalico L, Charitos IA, Kolveris N, et al. Philosophy and Hippocratic Ethic in Ancient Greek Society: Evolution of Hospital - Sanctuaries. Open Access Maced J Med Sci. 2019;7(19):3353-3357. Published 2019 Oct 13. doi:10.3889/oamjms.2019.474

28. Shell GR. Bargaining with the devil without losing your soul. In: Menkel-Meadow C, Wheeler M, eds. What's fair: Ethics for negotiators. Jossey-Bass; 2004.

29. Young M. Sharks, Saints, and Samurai: The Power of Ethics in Negotiations. Negot J. 2008;24(2): 145-155. doi: 10.1111/j.1571-9979.2008.00174.x

30. Nitobe I. Bushido: The Soul of Japan. Kodansha USA; 2012.

31. Adhikari S, Paudel K, Aro AR, Adhikari TB, Adhikari B, Mishra SR. Knowledge, attitude and practice of healthcare ethics among resident doctors and ward nurses from a resource poor setting, Nepal. BMC Med Ethics. 2016;17(1):68. Published 2016 Nov 8. doi:10.1186/s12910-016-0154-9

32. Beauchamp TL, Childress JF. Principles of biomedical ethics. $7^{\text {th }}$ ed. USA, New York: Oxford University Press; 2013.

33. Summers J, Morrison E. Principles of healthcare ethics. Health Care Ethics. $2^{\text {nd }}$ ed. Jones and Bartlett 
Publishers; 2009:41-58.

34. Dimonte M. L'abuso di esami radiologici: metafora della società post-moderna, dei nuovi media e dei consumi [The abuse of radiological diagnostic tests as a metaphor of the post-modern, new-media and consumerism society]. Recenti Prog Med.2008;99(3):125-128.

35. Rothberg MB, Sivalingam SK, Kleppel R, Schweiger M, Hu B, Sepucha KR. Informed Decision Making for Percutaneous Coronary Intervention for Stable Coronary Disease. JAMA Intern Med.2015;175(7):1199-1206. doi:10.1001/jamainternmed.2015.1657

36. Nishigori H, Harrison R, Busari J, Dornan T. Bushido and medical professionalism in Japan. Acad Med. 2014;89(4):560-563. doi:10.1097/ACM.0000000000000176

37. Merck LH, Ward LA, Applegate KE, Choo E, Lowery-North DW, Heilpern KL. Written Informed Consent for Computed Tomography of the Abdomen/Pelvis is Associated with Decreased CT Utilization in Low-Risk Emergency Department Patients. West J Emerg Med. 2015;16(7):1014-1024. doi:10.5811/westjem.2015.9.27612

38. Emanuel EJ, Emanuel LL. Four models of the physician-patient relationship. JAMA. 1992;267(16):2221-2226.

39. Cialdini RB, Griskevicius V. Social influence. In: Baumeister RF, Finkel EJ, eds. Advanced Social Psychology: The State of the Science. Oxford University Press; 2010: 385-417.

40. Präg P, Wittek R, Mills MC. The educational gradient in self-rated health in Europe: Does the doctor-patient relationship make a difference? Acta Sociol. 2017;60(4):325-341. https://doi.org/10.1177/0001699316670715

41. Dodaro A, Recchia V. Uso inappropriato dell'imaging ionizzante. Il nodo del consenso informato: dal modello "evento" al modello "processo" [Inappropriateness in ionizing imaging. The central node of the informed consent: from "event" model to "process" model].Recenti Prog Med. 2011;102(11):421-431. doi:10.1701/975.10606

42. Gruman J, Rovner MH, French ME, et al. From patient education to patient engagement: implications for the field of patient education.Patient Educ Couns. 2010;78(3):350-356. doi:10.1016/j.pec.2010.02.002

43. Martin DJ, Garske JP, Davis MK. Relation of the therapeutic alliance with outcome and other variables: a meta-analytic review. J Consult Clin Psychol. 2000;68(3):438-450.

44. Rovai D, Bonaguidi F. One-dimensional patient. J Am Coll Cardiol. 2015;65(7):757-758. doi:10.1016/j.jacc.2014.10.072

45. Levinson W, Hudak P, Tricco AC. A systematic review of surgeon-patient communication: strengths and opportunities for improvement.Patient Educ Couns. 2013;93(1):3-17. doi:10.1016/j.pec.2013.03.023

46. Ploug T, Holm S. Informed consent and routinisation. J Med Ethics. 2013;39(4):214-218. doi:10.1136/medethics-2012-101056

47. Mesoudi A. How cultural evolutionary theory can inform social psychology and vice versa. Psychol Rev. 2009;116(4):929-952. doi:10.1037/a0017062

48. Hornby AS, Deuter M, Bradbery J, Turnbull J, Heyning-Plate LSC, Holloway S, Hancock M, Ashby M. Oxford Advanced Learner's Dictionary of Current English. $9^{\text {th }}$ ed. 2005, at 548.

49. White M. Equity - A General Principle of Law Recognised by Civilised Nations. QUTLJJ. 2004;4(1). doi: https://doi.org/10.5204/qutlr.v4i1.177

50. Farnadi G, Babaki B, Getoor L. A Declarative Approach to Fairness in Relational Domains. IEEE Data Eng Bull. 2019;42:36-48.

51. Lussiez C. Informing the patient on medical liability: what can we do? World Hosp Health Serv. 2009;45(1):15-16.

52. Goff SL, Mazor KM, Ting HH, Kleppel R, Rothberg MB. How cardiologists present the benefits of percutaneous coronary interventions to patients with stable angina: a qualitative analysis. JAMA Intern Med. 2014;174(10):1614-1621. doi:10.1001/jamainternmed.2014.3328

53. Schaad B, Bourquin C, Panese F, Stiefel F. How physicians make sense of their experience of being involved in hospital users' complaints and the associated mediation. BMC Health Serv Res.2019;19(1):73. Published 2019 Jan 28. doi:10.1186/s12913-019-3905-8 
54. Herrman MS. The Blackwell Handbook of Mediation: Bridging Theory, Research, and Practice. $1^{\text {st }}$ ed. Wiley-Blackwell; 2009, 472 pp.

55. Maute JL. Mediator Accountability: Responding to Fairness Concerns.J Dispute Resolut. 1990;2:4. Available at:https://scholarship.law.missouri.edu/jdr/vol1990/iss2/4.

56. Recchia V, Dodaro A, Braga L. Event-based versus process-based informed consent to address scientific evidence and uncertainties in ionising medical imaging. Insights Imaging. 2013;4(5):647-653. doi:10.1007/s13244-013-0272-6

57. Terranova G, Ferro M, Carpeggiani C, et al. Low quality and lack of clarity of current informed consent forms in cardiology: how to improve them [published correction appears in JACC Cardiovasc Imaging. 2012 Nov;5(11):1190]. JACC Cardiovasc Imaging.2012;5(6):649-655.

\section{Funding Statement}

There are no funders to report for this submission.

\section{Conflict of Interest Disclosure}

The authors declare that they have no conflict of interest.

Ethics and consent Not required.

Data Availability Statement

Data sharing is not applicable to this article as no new data were created or analyzed in this study.

\section{Hosted file}

2_Main Document_Tables.docx available at https://authorea.com/users/458396/articles/554956the-samurai-physician-negotiation-styles-for-informed-consent-and-conflict-mediation 